Research Article

\title{
Changes in Extreme Precipitation in the Mekong Basin
}

\author{
Lu Liu $\mathbb{D},{ }^{1,2}$ Peng Bai $\mathbb{D},{ }^{1}$ Changming Liu, ${ }^{1}$ Wei Tian $\mathbb{D},{ }^{1,2}$ and Kang Liang $\mathbb{D}^{1}$ \\ ${ }^{1}$ Key Laboratory of Water Cycle and Related Land Surface Processes, \\ Institute of Geographic Sciences and Natural Resources Research, Chinese Academy of Sciences, Beijing, China \\ ${ }^{2}$ University of Chinese Academy of Sciences, Beijing, China
}

Correspondence should be addressed to Peng Bai; baip@igsnrr.ac.cn

Received 31 May 2020; Revised 12 September 2020; Accepted 3 October 2020; Published 22 October 2020

Academic Editor: Gwo-Fong Lin

Copyright (C) $2020 \mathrm{Lu}$ Liu et al. This is an open access article distributed under the Creative Commons Attribution License, which permits unrestricted use, distribution, and reproduction in any medium, provided the original work is properly cited.

\begin{abstract}
Extreme precipitation events can trigger many natural disasters like floods, mudslides, and landslides. Understanding historical changes in extreme precipitation is critical for disaster prevention and risk assessment. The Mekong River Basin (MB) is vulnerable to natural disasters related to extreme precipitation. In the past ten years, the $\mathrm{MB}$ has experienced some destructive extreme precipitation events. Our concern is whether the historical extreme precipitation events in the MB have increased in a warming climate. This study investigates the spatiotemporal changes in extreme precipitation in the MB from 1951 to 2015 using a high-quality precipitation product and eight indices of extreme precipitation. These indices consistently indicate that the trend in extreme precipitation in the Upper Mekong Basin (UMB) is opposite to that in the Lower Mekong Basin (LMB). Extreme precipitation has generally decreased in the UMB but increased in the LMB. The areas with significant increasing extreme precipitation are mainly located in Laos, Vietnam, and Cambodia. The areas with a statistically significant decline in extreme precipitation primarily occur in the Lancang (China's section of the Mekong river) and Thailand. Also, the magnitude of changes in extreme precipitation is significantly larger in the LMB than that in the UMB, which potentially increases flooding risks in the LMB. The findings from this study are useful for guiding disaster-prevention efforts in the MB.
\end{abstract}

\section{Introduction}

Climate change and human activities have intensified the global water cycle over the past decades, leading to an increase in extreme precipitation in many regions of the world $[1,2]$. As the climate warms, the rising temperature causes more water to evaporate from lands and oceans into the atmosphere, and the warmer air can hold more water vapor. As a result, the frequency and intensity of extreme precipitation are expected to increase in a warming climate $[3,4]$. However, changes in extreme precipitation with global warming vary in different regions [5]. For example, it was reported that historical extreme precipitation events have decreased in some subtropical regions [6] but have increased in some tropical areas [1, 4]. Increasing extreme precipitation can trigger more natural disasters such as floods and landslides, leading to devastating impacts on human society. According to the statistics from the Food and Agriculture Organization of the United Nations (FAO), floods have long been one of the most destructive natural disasters in the world in terms of death toll since the 1900s [7]. Global flood damages are estimated to reach billions of dollars, and thousands of lives are killed by floods every year. In the United States, floods are the second deadliest of all weather-related hazards, and annual economic loss caused by rainstorm floods had grown from $\$ 100$ million in the 1950 s to $\$ 6$ billion in the 1990 s [8]. The increasing loss caused by catastrophic rainfall-related hazards has prompted many scholars to focus on global and regional extreme precipitation trends.

The transboundary Mekong Basin (MB) is located in Southeast Asia, characterized by a monsoon climate and a complex topography [9]. The income levels of the countries where the Mekong River flows are generally low, and most of the population lives along the river [10]. Thus, these countries generally have poor resistance to devastating extreme precipitation events. Many studies have examined precipitation-related changes in the $\mathrm{MB}$, usually focusing on average conditions rather than extremes [11-14]. Eastham et al. [11] reported that the MB generally experienced drier 
and longer dry seasons and wetter and shorter rainy seasons based on the observations and outputs of climate models. Lacombe et al. [13] further found that the increase in precipitation during the wet season contributed to the increase in annual precipitation in most areas of the MB. Wu et al. [14] found that annual precipitation in the upper reaches of the MB increased slightly from 1960 to 2000 while it decreased significantly after 2000 . In the lower reaches of the $\mathrm{MB}$, annual precipitation increased slightly in Vietnam and Cambodia and decreased significantly in western Thailand during 1961-2007 [12]. Several studies have also investigated the changes in extreme precipitation in the MB [15-18], but they usually used limited extreme precipitation indices or focused on parts of the basin.

In this study, we aim to offer a general investigation of extreme precipitation changes in the $\mathrm{MB}$ over the past decades. To achieve this, an observation-based precipitation product and a set of extreme precipitation indices were used. The structure of this paper is arranged as follows. We introduce the study area, data, and methods in section 2 . Section 3 shows the spatiotemporal changes in extreme precipitation from 1950 to 2015 across the MB. Section 4 discusses the potential effects of extreme precipitation changes on floods in the $\mathrm{MB}$ and the uncertainty sources of assessment results. Conclusions are presented in section 5 .

\section{Data and Methods}

2.1. Study Area. The Mekong River is the 11th longest river of the world [9], with a total length of $4600 \mathrm{~m}$ and a drainage area of $795,000 \mathrm{~km}^{2}$ (Figure 1). The river originates from the Tibetan Plateau and ends into the South China Sea, flowing southward through six nations. The Upper Mekong Basin (UMB) covers parts of southwestern China and eastern Myanmar, and China's portion of the upper Mekong is called Lancang. The Lower Mekong Basin (LMB) overlaps partial Laos, Thailand, Cambodia, and Vietnam. The MB spans from a snow-covered alpine area at more than 5000 meters above sea level (m. a. s. 1.) to a tropical low-flat area, with complex and diverse climate and landscape features [9]. The climate varies from the cool temperate climate in the north to the tropical climate in the south. The average annual temperature transitions from $1-3^{\circ} \mathrm{C}$ at the northern end to $26-29^{\circ} \mathrm{C}$ at the southern end, and the average annual precipitation ranges from $400 \mathrm{~mm}$ upstream to $2000 \mathrm{~mm}$ downstream [19]. The LMB has many low-income nations, such as Laos, Vietnam, and Cambodia, with a per capita GDP far below the global average [20]. The economic development of these areas mainly depends on agriculture and fishing, and these industries are susceptible to extreme precipitation events. Thus, understanding the changes in extreme precipitation across the $\mathrm{MB}$ is essential to reduce the disaster risk induced by extreme precipitation.

2.2. Data. High-quality precipitation data are important to describe the spatiotemporal changes in extreme precipitation. As advances in satellite and computing techniques, many precipitation datasets were developed based on remote sensing, reanalysis, and observations [21-23]. The three commonly used satellite precipitation products include Tropical Rainfall Measuring Mission (TRMM) [24], Global Precipitation Mission (GPM) [25], and Precipitation Estimation from Remotely Sensed Information using an Artificial Neural Network-Climate Data Record (PERSIANNCDR) [26]. Two global reanalysis datasets (Interim ECMWF Re-Analysis (ERA-Interim) [27] and Climate Forecast System Reanalysis (CFSR) [28]) are also applicable in the MB. Several studies have indicated that satellite products (e.g., GPM and TRMM) overall perform better than reanalysis products in capturing precipitation changes in the MB [21-23]. However, the satellite products have relatively short data time series (less than 30 years) and are not suitable to detect long-term precipitation trends.

APHRODITE (Asian Precipitation Highly Resolved Observational Data Integration toward Evaluation) is a continental-scale daily gridded precipitation product that is based on a dense network of rain gauges for Asia [21, 29]. This product provides more than 60 years of gridded precipitation and is a good candidate for analyzing the longterm shifts in extreme precipitation in the MB. It covers the period of $1951-2015$, with a spatial resolution of $0.25^{\circ} \times 0.25^{\circ}$. To ensure the reliability and accuracy of the data, a strict data quality control scheme was performed by data generators to remove invalid records in dataset generation, and a sophisticated Optimal Interpolation method was used to weaken orographic effects on precipitation [29]. APHRODITE has been selected as a "ground truth" to evaluate other precipitation products in data-sparse areas over Asia $[28,30]$.

\subsection{Methods}

2.3.1. Extreme Precipitation Indices. Extreme precipitation can result from either high precipitation rates in short periods or excessive accumulated precipitation within one or several days [31]. To better describe precipitation extremes, we used eight extreme precipitation indices defined by the Expert Team on Climate Change Detection and Indices (ETCCTI) [32], which have been widely used to detect extreme precipitation changes $[18,33,34]$. These indices are divided into four categories: threshold indices, percentile indices, absolute indices, and other indices [2]. Table 1 provides specific descriptions of these indices. Threshold indices represent the annual total number of days when the daily precipitation amount is larger than a fixed number, such as moderate rainfall days (R10 mm) and heavy rainfall days $(\mathrm{R} 20 \mathrm{~mm})$. Percentile indices include the total amount of daily precipitation falling above the 95th (R95p) and 99th (R99p) percentiles per year. Absolute indices are defined as the annual maximum of accumulated precipitation in a given period, including the peak of precipitation within five days (Rx5day) or one day (Rx1day). Other indices used here are annual total precipitation from wet days (PRCTOT) and daily precipitation intensity (SDII). Overall, the first three categories cover multiple aspects of extreme precipitation, such as frequency and intensity. The last category (PRCTOT 


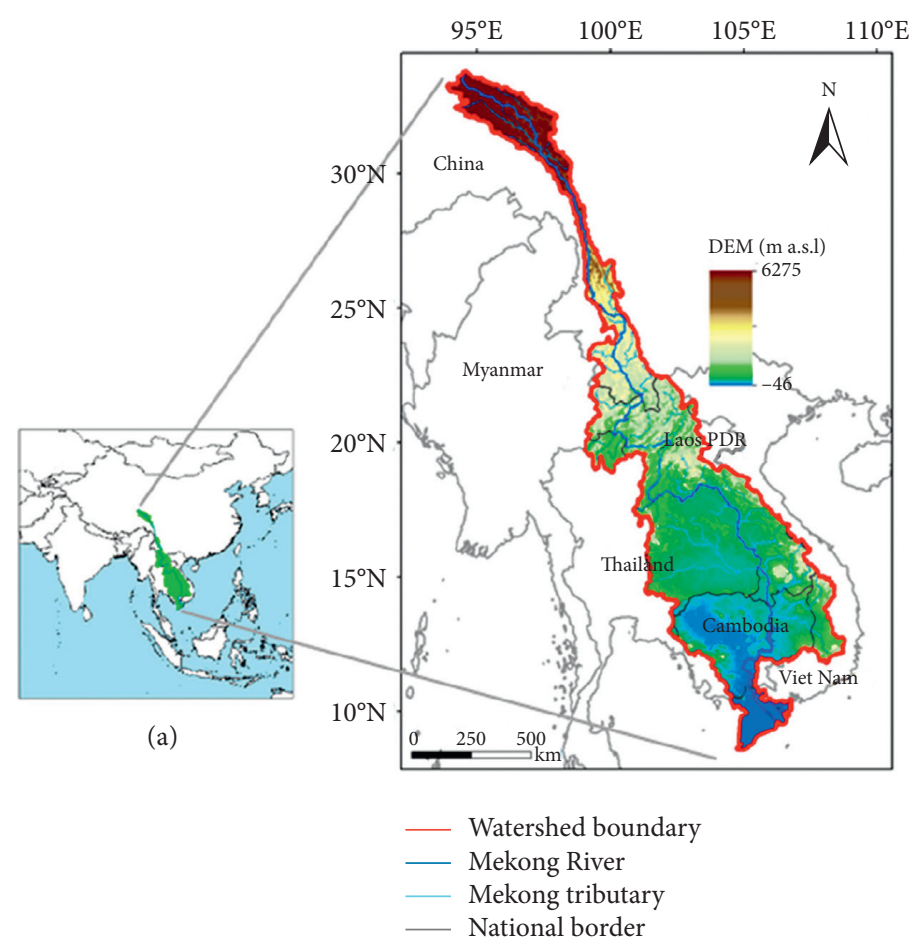

(b)

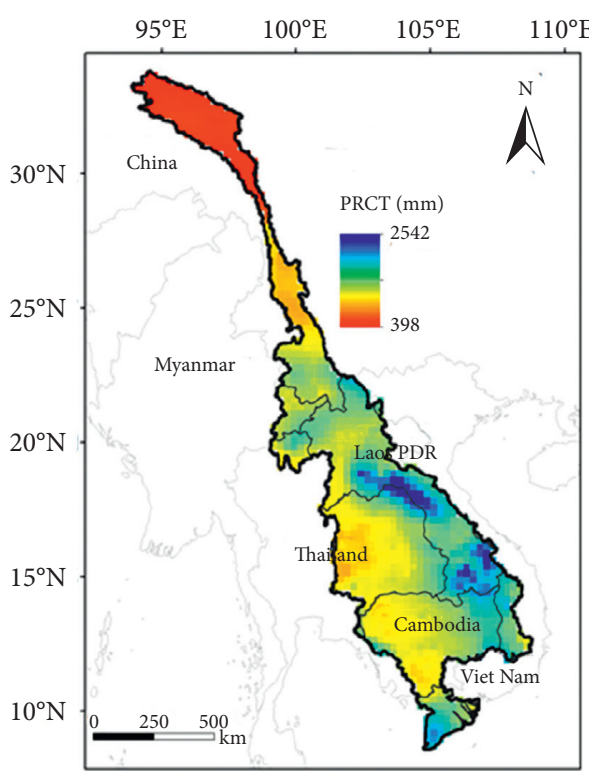

National border

Watershed boundary

(c)

Figure 1: The location (a), elevation (b), and annual average precipitation (c) of the Mekong Basin.

TABle 1: Summary of eight precipitation indices. Note: PR is precipitation; wet days are when daily PR is $\geq 1.0 \mathrm{~mm}$.

\begin{tabular}{|c|c|c|c|c|}
\hline Category & Index & Description & Definition & Unit \\
\hline \multirow{2}{*}{ Threshold indices } & $\mathrm{R} 10 \mathrm{~mm}$ & Number of moderate PR days & Annual number of days when daily $P R$ is $\geq 10 \mathrm{~mm}$ & days \\
\hline & $\mathrm{R} 20 \mathrm{~mm}$ & Number of heavy PR days & Annual number of days when daily PR is $\geq 20 \mathrm{~mm}$ & days \\
\hline \multirow{2}{*}{ Percentile indices } & R95p & Total PR from over wet days & Annual sum when daily PR is $>95$ th percentile & $\mathrm{mm}$ \\
\hline & $\mathrm{R} 99 \mathrm{p}$ & Total PR from terribly wet days & Annual sum when daily PR is $>99$ th percentile & $\mathrm{mm}$ \\
\hline \multirow{2}{*}{ Absolute indices } & Rx5day & Max. 5-day PR & Annual maximum of 5-day PR total & $\mathrm{mm}$ \\
\hline & Rx1day & Max. 1-day PR & Annual maximum of 1-day PR total & $\mathrm{mm}$ \\
\hline Other indices & $\begin{array}{l}\text { PRCPTOT } \\
\text { SDII }\end{array}$ & $\begin{array}{l}\text { Annual total wet-day PR } \\
\text { Daily PR intensity }\end{array}$ & $\begin{array}{c}\text { Annual sum from wet days } \\
\text { Annual average daily PR from wet days }\end{array}$ & $\underset{\mathrm{mm} / \mathrm{day}}{\mathrm{mm}}$ \\
\hline
\end{tabular}

and SDII) does not describe extreme precipitation, but their changes are more statistically robust than extremes computed from the tail of the distribution of daily rainfall.

\subsubsection{Mann-Kendall and Sen's Method. The Mann-Kendall} trend test was used to determine the significance of changes in precipitation indices [35]. Sen's method was adopted to estimate the magnitude of changes [36]. The two methods were taken for computing the significance and slope of the time series trend of each grid in the APHRODITE precipitation dataset. The two methods are simple and robust. The used data are not required to obey any statistical distribution, and missing values are allowed [37]. Thus, these methods have been frequently used in analyzing the hydrometeorological data series [38, 39].
The trend testing was done at the 0.05 significance level. Equation (1) shows how to derive the Mann-Kendall standard normal test statistic $Z$ [35]:

$$
Z= \begin{cases}\frac{S-1}{\sqrt{\operatorname{Var}(S)}}, & S>0, \\ 0, & S=0, \\ \frac{S+1}{\sqrt{\operatorname{Var}(S)}}, & S<0 .\end{cases}
$$

The $Z$ comes from the statistic $S$, which is computed as follows: 


$$
S=\sum_{i=1}^{n-1} \sum_{j=j+1}^{n} \operatorname{sgn}\left(x_{j}-x_{i}\right)
$$

where $n$ is the size of the data series $(n>10), x_{j}$ and $x_{i}$ are the numerical values ranked in the place $j$ and $i(j>i)$ in the time series, and the $\operatorname{sgn}\left(x_{j}-x_{i}\right)$ is the sign function expressed by the following equation:

$$
\operatorname{sgn}\left(x_{j}-x_{i}\right)= \begin{cases}+1, & x_{j}-x_{i}>0 \\ 0, & x_{j}-x_{i}=0 \\ -1, & x_{j}-x_{i}<0\end{cases}
$$

The variance in (1) is calculated as follows:

$$
\operatorname{Var}(S)=\frac{n(n-1)(2 n-5)-\sum_{i=1}^{m} t_{i}\left(t_{i}-1\right)\left(2 t_{i}+5\right)}{18},
$$

where $n$ is the size of the data series $(n>10), t_{i}$ is the count of values in the $i$-th data group, and $m$ is the count of tied groups, which are subsets having the same value in the time series.

The magnitude of the trend was estimated by using Sen's slope estimator [36]. Sen's method uses a linear model to estimate the slope of the trend, as shown in the following equation:

$$
b=\operatorname{Median}\left(\frac{x_{j}-x_{i}}{j-i}\right),
$$

where $b$ is the estimated trend slope and Median function is used to get the median of the data series. The sign of $b$ indicates whether the trend is upward or downward, and its value reflects the steepness of the trend.

\section{Results}

3.1. Changes in Threshold Indices. Figure 2 displays spatial patterns of trend in moderate rainfall days $(\mathrm{R} 10 \mathrm{~mm})$ and heavy rainfall days $(\mathrm{R} 20 \mathrm{~mm}$ ) for the period 1951-2015. The trend in $\mathrm{R} 10 \mathrm{~mm}$ shows a similar spatial pattern to that in $\mathrm{R} 20 \mathrm{~mm}$, dominated by uptrends in the basin. R10 $\mathrm{mm}$ increases $(p<0.05)$ in $64 \%$ of the basin and significantly increases in $28 \%$ of the basin. R20 mm increases in $63 \%$ of the basin and significantly increases in $32 \%$ of the basin. Areas with a significant increase in $\mathrm{R} 10 \mathrm{~mm}$ and $\mathrm{R} 20 \mathrm{~mm}$ mainly situate in Laos, Vietnam, and Cambodia, while statistically significant decreasing trends in the two indices occur in the Lancang and Thailand.

Given the huge differences in climatic conditions between the two regions, we separately analyzed the temporal changes of extreme precipitation indices in the UMB and the LMB (Figure 3). The frequency of moderate $(\mathrm{R} 10 \mathrm{~mm})$ and heavy $(\mathrm{R} 20 \mathrm{~mm})$ rainfall days significantly $(p<0.05)$ decreases in the UMB but significantly $(p<0.05)$ increases in the LMB during the period 1951-2015. The increase rates of $\mathrm{R} 10 \mathrm{~mm}$ and $\mathrm{R} 20 \mathrm{~mm}$ in the LMB are 0.9 and 0.4 days/ decade, while the decrease rates of the two indices in the UMB are -0.4 and -0.1 days/decade, respectively.
3.2. Changes in Percentile Indices. The total precipitation from over wet days (R95p) or terribly wet days (R99p) in a year can reflect the intensity of extreme precipitation. Figure 4 demonstrates the spatial trend patterns of the two indices across the MB. The trends in two indices overall exhibit a similar spatial distribution. Areas with a significant increasing trend $(p<0.05)$ in R95p and R99p account for $21 \%$ and $20 \%$ of the basin areas, respectively. These areas are primarily located in Laos, Vietnam, and Cambodia. In contrast, areas with a significant decreasing trend in R95p and R99p mainly exist in the Lancang and Thailand, accounting for $22 \%$ and $25 \%$ of the basin area, respectively. Temporally, both indices present opposite trends between the UMB and the LMB (Figure 5), showing an uptrend in the LMB and a downtrend in the UMB. Only the trend of R99p in the UMB is statistically significant $(p<0.05)$.

3.3. Changes in Absolute Indices. Unlike percentile indices, the maximum of precipitation within five days (Rx5day) or one day (Rxlday) focuses on consecutive-days heavy precipitation. Spatially, Rx5day and Rx1day also show a similar pattern of trend during the study period (Figure 6). Areas with a statistically significant uptrend $(p<0.05)$ in $\mathrm{Rx} 5$ day and Rxlday mainly concentrate in Laos, Vietnam, and Cambodia, accounting for $12 \%$ and $15 \%$ of the basin, respectively. Areas with a significant downtrend in Rx5day and Rx1day mainly occur in the Lancang and Thailand, and the percentage of these areas in the entire basin is $12 \%$ for Rx5day and 23\% for Rx1day. Also, the magnitude of change in Rx5day is apparently larger than that in Rx1day. Similar to other extreme indices, temporal changes in Rx5day and Rxlday are increased in the UMB but decreased in the LMB (Figure 7) throughout the study period.

3.4. Changes in Other Indices. Annual total precipitation (PRCTOT) and daily precipitation intensity (SDII) focus on the mean aspect of precipitation and can provide a context for understanding changes in extreme precipitation better. Figure 8 illustrates the spatial distribution of trends in PRCTOT and SDII from 1951 to 2015. The trend in SDII shows a similar spatial pattern to that in extreme indices, whereas PRCTOT shows a certain degree of difference in the spatial distribution of trends from extreme indices. The differences are noticeable in the northern Lancang and eastern Thailand, where most extreme precipitation indices decrease while PRCTOT increases.

Figure 9 shows the temporal change in PRCTOT and SDII during the study period. Similar to other precipitation indices, the two indices present opposing trends between the $\mathrm{UMB}$ and the LMB. PRCTOT significantly increases by $21.9 \mathrm{~mm}$ per decade $(p<0.05)$ in the LMB but insignificantly decreases by $2.8 \mathrm{~mm}$ per decade in the UMB. SDII exhibits a week trend in the LMB and a significant negative trend $(p<0.05)$ in the UMB. 


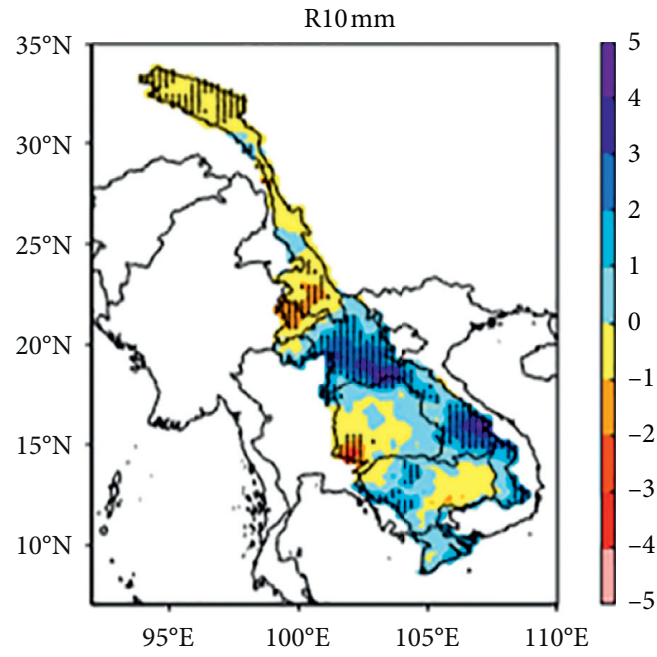

(a)

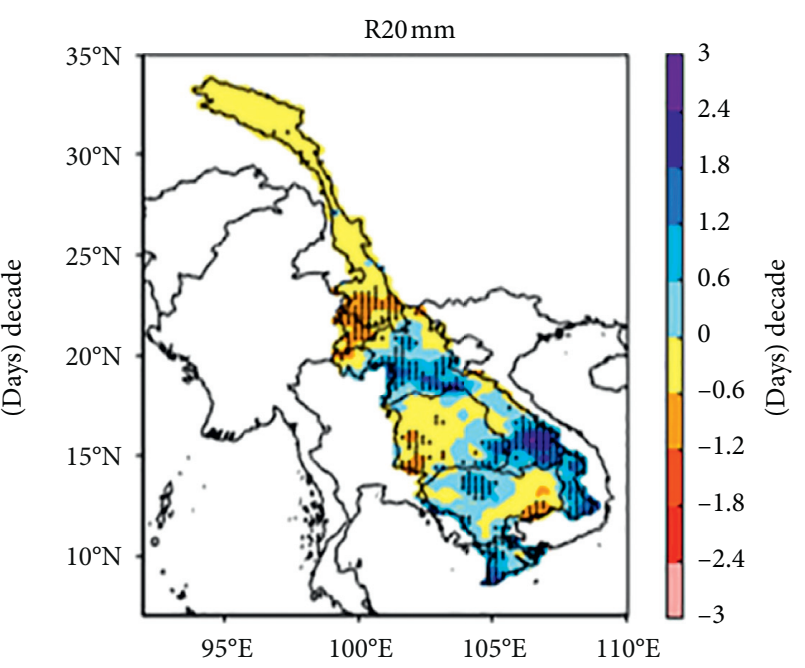

(b)

FIgUre 2: Spatial distribution of trend in R10 $\mathrm{mm}$ and R20 mm in the MB over 1951-2015. The black dots indicate that the trend in the grid is significant $(p<0.05)$ under the Mann-Kendall test.

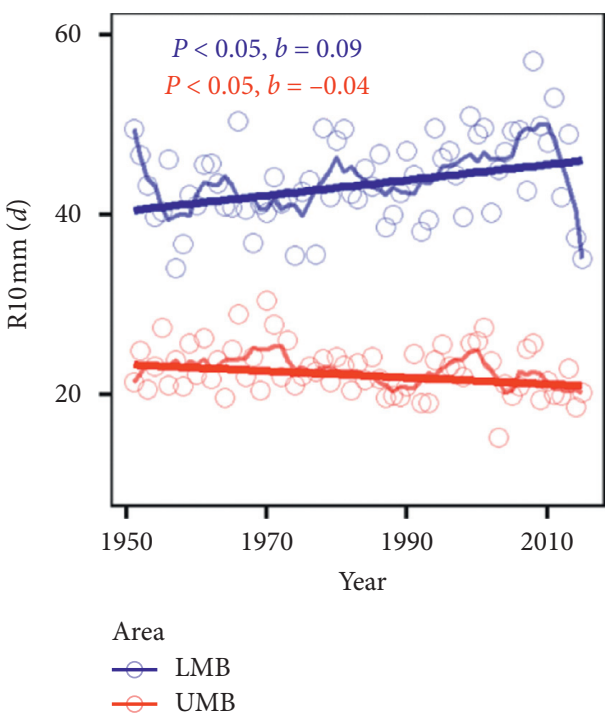

(a)

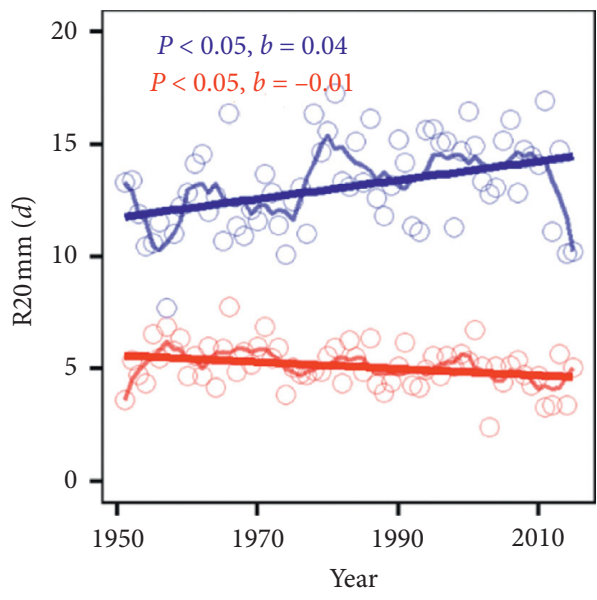

Area

$\odot$ LMB

(b)

Figure 3: Temporal trends in R10 mm and R20 mm averaged across the UMB and the LMB over 1951-2015. The lines represent linear trends of precipitation indices, and the polylines indicate the five-year moving averages of the indices.

\section{Discussion}

In this study, we examined the trend in eight extreme precipitation indices in the MB over 1951-2015 based on the APHRODITE dataset. All extreme precipitation indices consistently show opposite trends between the LMB and the $\mathrm{UMB}$, with a decrease in the UMB and an increase in the LMB. This conclusion is consistent with the previous analysis of extreme precipitation in some parts of the basin $[15,40]$. For example, Chen et al. found a decline in $\mathrm{R} 10 \mathrm{~mm}$, R20 mm, Rx5day, and R95p in the UMB from 1960 to 2012 [15]. In addition, the magnitude of changes in extreme precipitation in the LMB (uptrend-dominated) is significantly larger than that in the UMB (downtrend-dominated), which can potentially exacerbate flooding risks in the downstream of the basin. This result confirms the findings of O'Gorman et al. [41], who revealed that the sensitivity of extreme precipitation to global warming in low latitudes is usually larger than that in high latitudes by climate model simulations.

The change in annual precipitation is overall consistent with that in extreme precipitation in most areas, excluding the northern Lancang and eastern Thailand, where extreme precipitation has decreased while annual precipitation has 


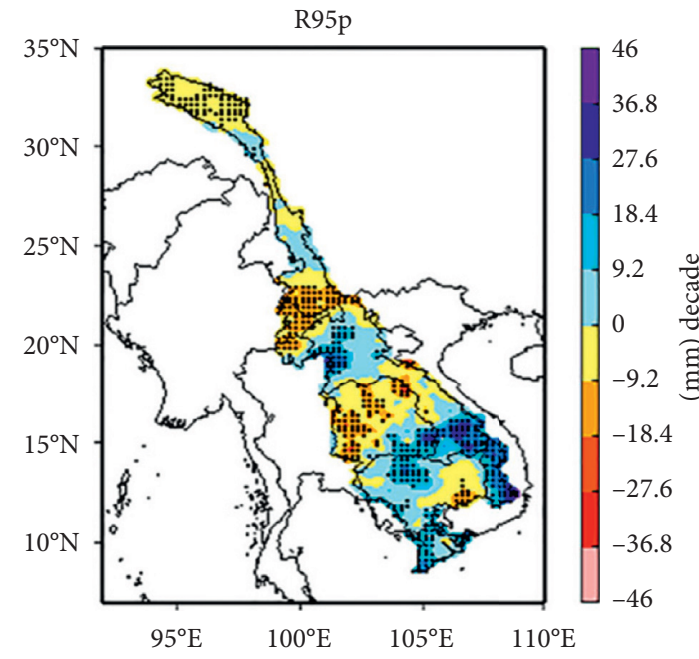

(a)

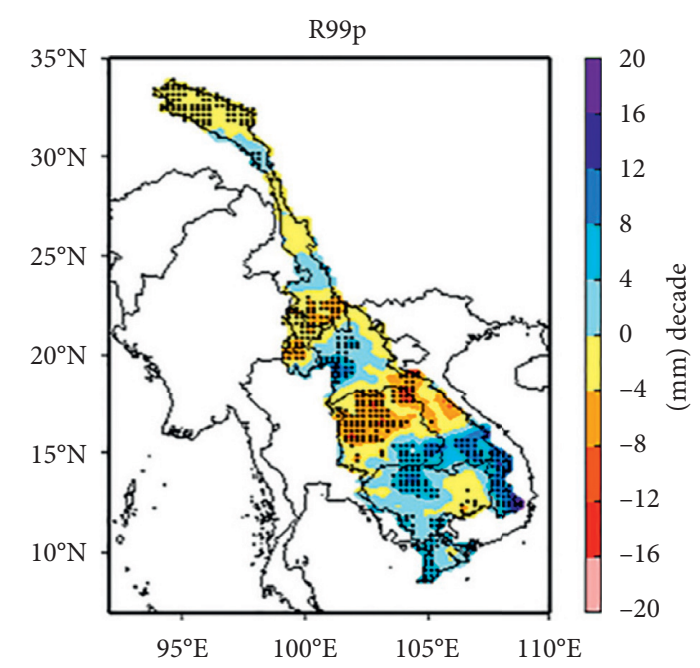

(b)

FIgURE 4: Spatial distribution of trend in R95p and R99p in the MB over 1951-2015. The black dots indicate that the trend in the grid is significant $(p<0.05)$ under the Mann-Kendall test.

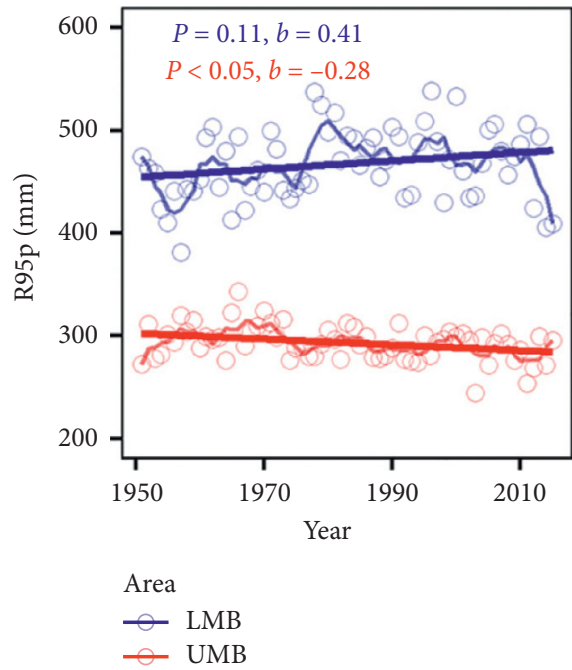

(a)

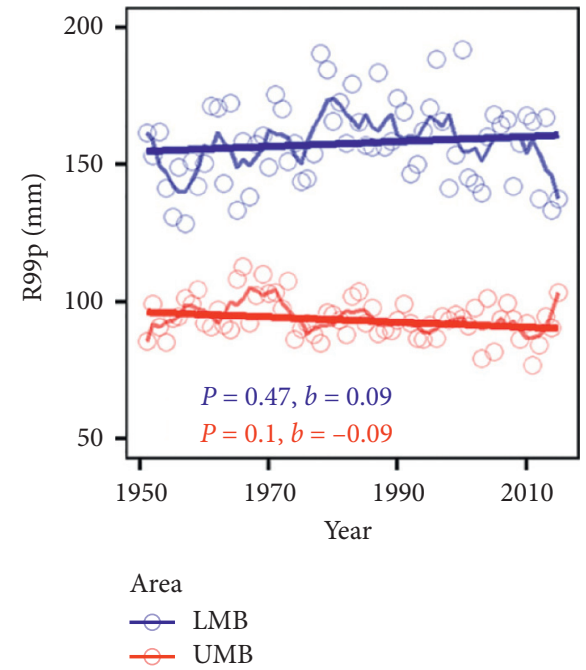

(b)

FIGURE 5: Temporal trends in R95p and R99p averaged across the UMB and the LMB over 1951-2015. The lines represent linear trends of precipitation indices, and the polylines indicate the five-year moving averages of the indices.

increased. The inconsistent change may be primarily attributed to the change in light rainfall [14]. An increased number of light rainfall days is likely to offset the reduction in extreme precipitation and leads to the opposing trends between extreme precipitation and annual precipitation [42]. The increase in the number of light rainfall days and the decrease in extreme precipitation are more beneficial to agricultural production. In addition, our results also suggest that extreme precipitation indices with larger intensity tend to have a smaller magnitude of change. This is in line with some previous studies $[2,18]$.

The mean annual precipitation shows significant spatial differences in the $\mathrm{MB}$ and ranges from 398 to $2542 \mathrm{~mm}$
(Figure 1(c)). The large spatial variability of annual precipitation is attributed to the special topography characteristics of the basin [43]. The Mekong Delta is located in the tropics with relatively flat terrain, and tropical ocean cyclones bring abundant precipitation to this region in the rainy season. However, the areas above the Delta are mostly mountainous areas with complex terrain. The mountains block the transmission of water vapor from the ocean to the inland areas, resulting in huge spatial variability in annual precipitation in the basin.

In recent years, some areas in the LMB have experienced more and more extreme flooding events, causing severe damages to socioeconomics. For example, in 2000, extreme 


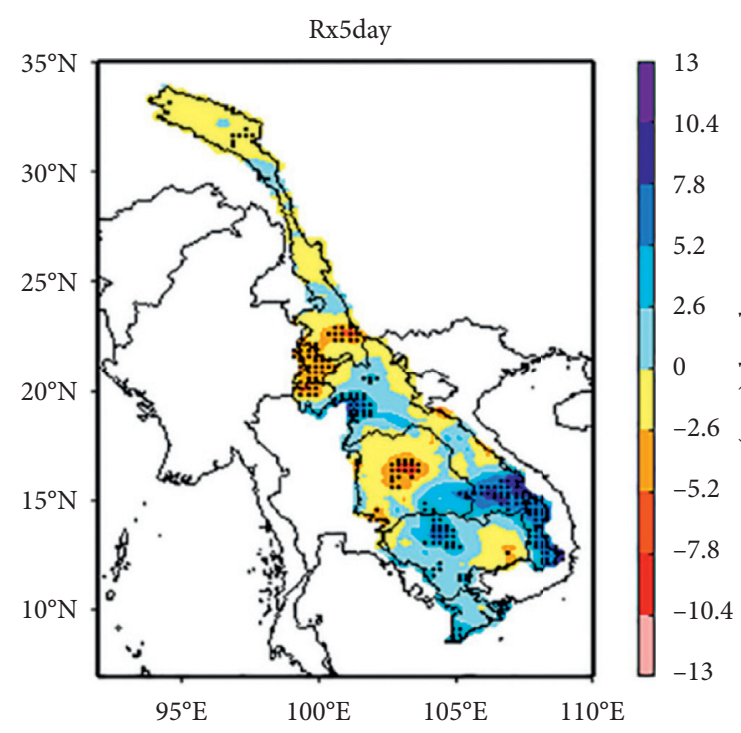

(a)

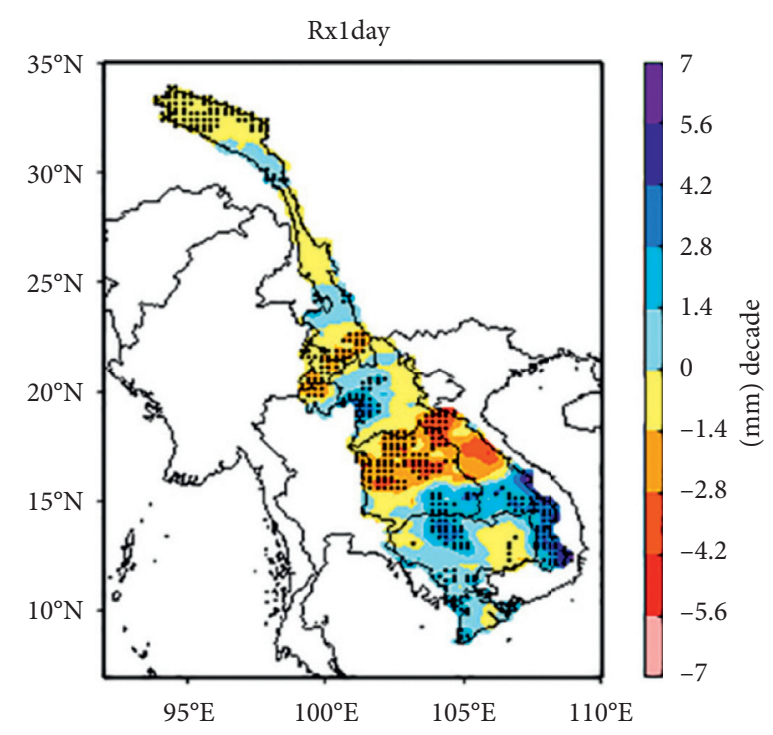

(b)

Figure 6: Spatial distribution of trend in Rx5day and Rx1day in the MB over 1951-2015. The black dots indicate that the trend in the grid is significant $(p<0.05)$ under the Mann-Kendall test.

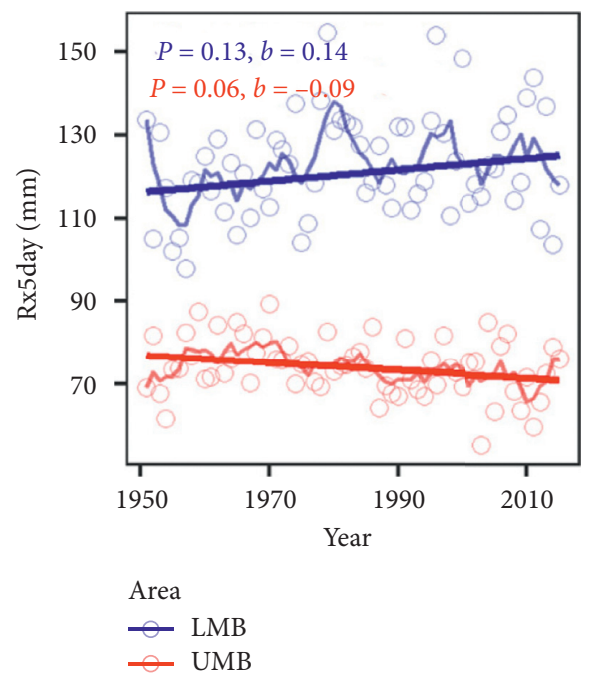

(a)

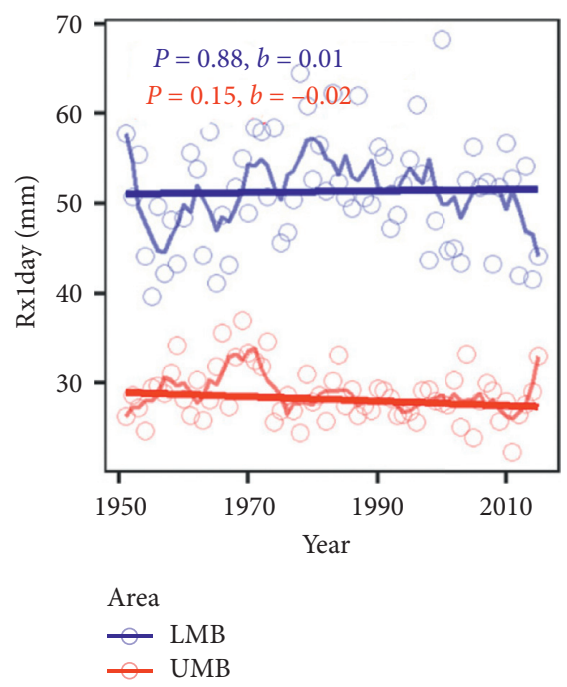

(b)

FIGURE 7: Temporal trends in Rx5day and Rx1day averaged across the UMB and the LMB over 1951-2015. The lines represent linear trends of precipitation indices, and the polylines indicate the five-year moving averages of the indices.

precipitation triggered one of the largest floods of the recent history in the Mekong Delta, killing more than 480 people and displacing thousands in the LMB [44]. In 2011, seasonal floods in Cambodia inundated 423,449 ha of farmland and affected 1.64 million people, causing an estimated economic loss of \$521 million [37]. The increase in extreme floods in the LMB is probably attributed to the increase in extreme precipitation in this region [45]. As global warming, the extreme precipitation events in the $\mathrm{MB}$ are projected to increase [43], which likely further exacerbates flood risks in this region. It is thus crucial to improve flood prevention infrastructure and strengthen international cooperation among riverside countries to adapt to increasing flood risks in the future. Unlike the LMB, one of the most frequent natural disasters in the UMB is not floods but droughts [43]. The annual precipitation in the UMB has decreased in recent years, resulting in an increase in drought events in this region $[14,46]$. The inconsistency of extreme precipitation changes between the UMB and the LMB highlights the importance of conducting data and information exchange, basin-wide monitoring, and joint assessment on Mekong water resources. 


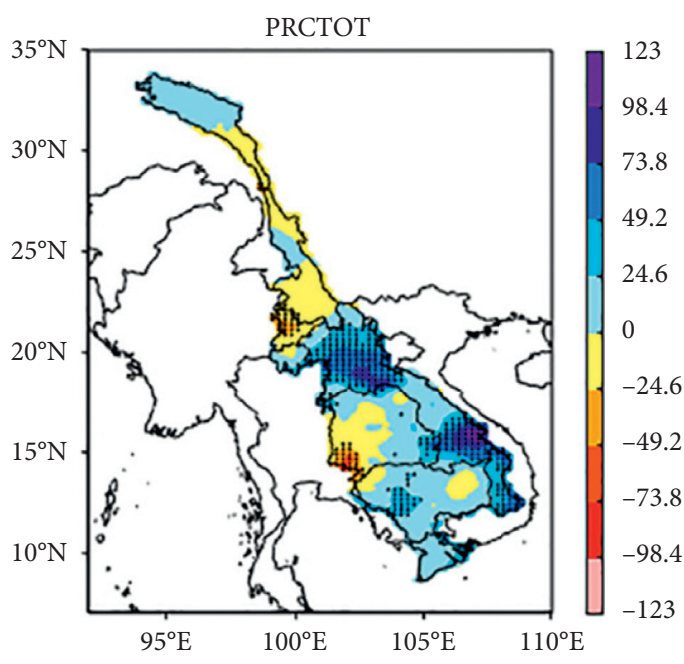

(a)

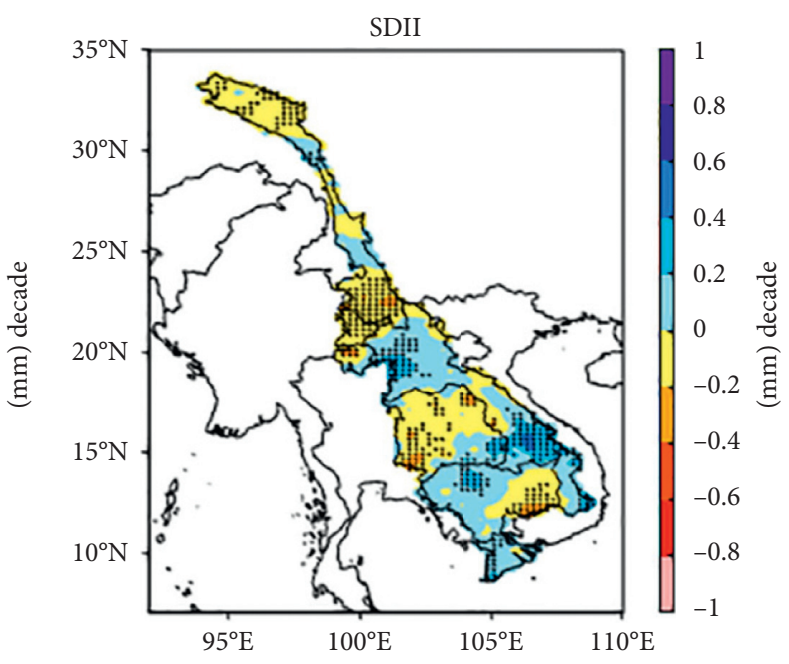

(b)

FIgURE 8: Spatial distribution of trend in PRCTOT and SDII in the MB over 1951-2015. The black dots indicate that the trend in the grid is significant $(p<0.05)$ under the Mann-Kendall test.

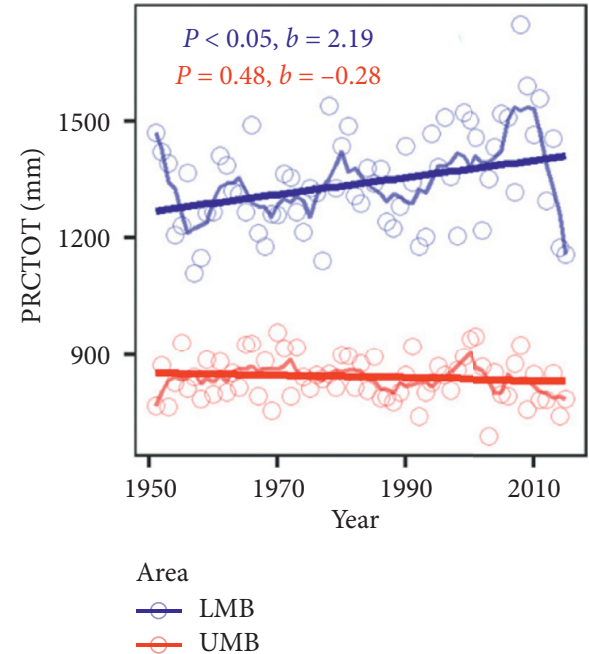

(a)

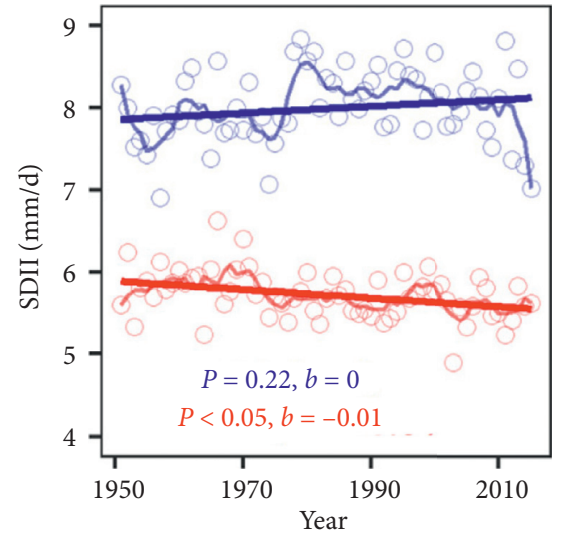

Area

$\neg$ LMB

(b)

FIGURE 9: Temporal trends in PRCTOT and SDII averaged across the UMB and the LMB over 1951-2015. The lines represent linear trends of precipitation indices, and the polylines indicate the five-year moving averages of the indices.

One of the uncertainty sources comes from the dataset of APHRODITE. Although this product has been used as reference data to assess other precipitation products in the MB [21], it still has a certain error in precipitation estimates compared with the gauge-based observations, particularly in areas with complex terrain and sparse gauge networks. For example, Ono el al. [47] found that extreme precipitation derived from the APHRODITE was lower than observations in Laos and Vietnam. Nevertheless, the product remains by far the most reliable precipitation product in this region since it employs a large number of rain gauges to generate precipitation estimates [29].

\section{Conclusion}

Based on a high-quality precipitation dataset and a series of ETCCTI precipitation indices, we investigated extreme precipitation changes in the Mekong basin from 1951 to 2015. Changes in extreme precipitation indices show great spatial differences across the basin. Statistically significant increasing extreme precipitation has mainly occurred in the downstream of the basin, such as Laos, Vietnam, and Cambodia. The upstream of the basin has been dominated by a decreasing trend in extreme precipitation. Also, the changed magnitude in extreme precipitation in the 
downstream of the basin is significantly larger than that in the upstream of this region. This could adversely affect downstream flood prevention. In most areas, annual total wet-day precipitation (PRCTOT) follows a similar trend to extreme precipitation. These changes in precipitation indices are in line with the frequent occurrence of floods in the downstream and droughts in the upstream in recent decades. Basin-wide cooperation in water resources management is necessary to reduce water disaster risks in the basin.

\section{Data Availability}

The data used to support the study are available within the article.

\section{Conflicts of Interest}

The authors declare that there are no conflicts of interest regarding the publication of this article.

\section{Acknowledgments}

We are grateful for the precipitation data support from the Research Institute for Human and Nature and the Meteorological Research Institute of Japan Meteorology Agency (http://www.chikyu.ac.jp/precip/). This research was supported by the Natural Science Foundation of China (Grant no. 51979263), the Second Tibetan Plateau Scientific Expedition and Research Program (STEP) (Grant no. 2019QZKK0903), the Program for "Bingwei" Excellent Talents in Institute of Geographic Sciences and Natural Resources Research, Chinese Academy of Sciences (Grant no. 2017RC204), and the Program for the Youth Innovation Promotion Association, Chinese Academy of Sciences (Grant no. 2019054).

\section{References}

[1] S. Westra, L. V. Alexander, and F. W. Zwiers, "Global increasing trends in annual maximum daily precipitation," Journal of Climate, vol. 26, no. 11, pp. 3904-3918, 2013.

[2] L. V. Alexander, X. Zhang, T. C. Peterson et al., "Global observed changes in daily climate extremes of temperature and precipitation," Journal of Geophysical Research: Atmospheres, vol. 111, no. D5, Article ID 006290, 2006.

[3] S. K. Min, X. Zhang, F. W. Zwiers, and G. C. Hegerl, "Human contribution to more-intense precipitation extremes," Nature, vol. 470, no. 7334, pp. 378-381, 2011.

[4] K. E. Kunkel, T. R. Karl, D. R. Easterling et al., "Probable maximum precipitation and climate change," Geophysical Research Letters, vol. 40, no. 7, pp. 1402-1408, 2013.

[5] N. F. Tandon, X. Zhang, and A. H. Sobel, "Understanding the dynamics of future changes in extreme precipitation intensity," Geophysical Research Letters, vol. 45, no. 6, pp. 2870-2878, 2018.

[6] S. Pfahl, P. A. O'Gorman, and E. M. Fischer, "Understanding the regional pattern of projected future changes in extreme precipitation," Nature Climate Change, vol. 7, no. 6, pp. 423-427, 2017.

[7] S. N. Jonkman, "Global perspectives on loss of human life caused by floods," Natural Hazards, vol. 34, no. 2, pp. 151-175, 2005.
[8] D. R. Easterling, G. A. Meehl, C. Parmesan et al., "Climate extremes: observations, modeling, and impacts," Science, vol. 289, no. 5487, pp. 2068-2074, 2000.

[9] Mekong River Commission (MRC), State of the Basin Report 2010, Mekong River Commission (MRC), Vientiane, Laos, 2010.

[10] S. Pech and K. Sunada, "Population growth and natural-resources pressures in the Mekong river basin," AMBIO: A Journal of the Human Environment, vol. 37, no. 3, pp. 219224, 2008.

[11] J. Eastham, F. Mpelasoka, M. Mainuddin et al., Mekong River Basin Water Resources Assessment: Impacts of Climate Change, Commonwealth Scientific and Industrial Research Organisation (CSIRO), Clayton, Australia, 2008.

[12] K. Artlert and C. Chaleeraktrakoon, "Modeling and analysis of rainfall processes in the context of climate change for Mekong, Chi, and Mun River Basins (Thailand)," Journal of Hydro-Environment Research, vol. 7, no. 1, pp. 2-17, 2013.

[13] G. Lacombe, C. T. Hoanh, and V. Smakhtin, "Multi-year variability or unidirectional trends? Mapping long-term precipitation and temperature changes in continental Southeast Asia using PRECIS regional climate model," Climatic Change, vol. 113, no. 2, pp. 285-299, 2012.

[14] F. Wu, X. Wang, Y. Cai, and C. Li, "Spatiotemporal analysis of precipitation trends under climate change in the upper reach of Mekong River basin," Quaternary International, vol. 392, pp. 137-146, 2016.

[15] F. Chen, H. Chen, and Y. Yang, "Annual and seasonal changes in means and extreme events of precipitation and their connection to elevation over Yunnan Province, China," Quaternary International, vol. 374, pp. 46-61, 2015.

[16] H. C. Thoeun, "Observed and projected changes in temperature and rainfall in Cambodia," Weather and Climate Extremes, vol. 7, pp. 61-71, 2015.

[17] A. Chen, C.-H. Ho, D. Chen, and C. Azorin-Molina, "Tropical cyclone rainfall in the Mekong river basin for 1983-2016," Atmospheric Research, vol. 226, pp. 66-75, 2019.

[18] Y. G. Li, D. He, J. M. Hu, and J. Cao, "Variability of extreme precipitation over yunnan province, China 1960-2012," International Journal of Climatology, vol. 35, no. 2, pp. 245-258, 2015.

[19] H. Lauri, T. Rasanen, and M. Kummu, "Using reanalysis and remotely sensed temperature and precipitation data for hydrological modeling in monsoon climate: Mekong River case study," Journal of Hydrometeorology, vol. 15, no. 4, pp. 1532-1545, 2014.

[20] P. Warr, "Poverty reduction and the composition of growth in the mekong economies," in Sustainable Economic Development, pp. 469-482, Elsevier, Amsterdam, Netherlands, 2015.

[21] A. Chen, D. Chen, and C. Azorin-Molina, "Assessing reliability of precipitation data over the Mekong River Basin: a comparison of ground-based, satellite, and reanalysis datasets," International Journal of Climatology, vol. 38, no. 11, pp. 4314-4334, 2018.

[22] W. Wang, H. Lu, T. Zhao et al., "Evaluation and comparison of daily rainfall from latest GPM and TRMM products over the Mekong River Basin," IEEE Journal of Selected Topics in Applied Earth Observations Remote Sensing, vol. 10, no. 6, pp. 2540-2549, 2017.

[23] C. J. Chen, S. U. Senarath, I. M. Dima-West, and M. P. Marcella, "Evaluation and restructuring of gridded precipitation data over the Greater Mekong Subregion," International Journal of Climatology, vol. 37, no. 1, pp. 180-196, 2017. 
[24] G. J. Huffman, D. T. Bolvin, E. J. Nelkin et al., "The TRMM multisatellite precipitation analysis (TMPA): quasi-global, multiyear, combined-sensor precipitation estimates at fine scales," Journal of Hydrometeorology, vol. 8, no. 1, pp. 38-55, 2007.

[25] A. Y. Hou, R. K. Kakar, S. Neeck et al., "The global precipitation measurement mission," Bulletin of the American Meteorological Society, vol. 95, no. 5, pp. 701-722, 2014.

[26] H. Ashouri, K.-L. Hsu, S. Sorooshian et al., "PERSIANNCDR: daily precipitation climate data record from multisatellite observations for hydrological and climate studies," Bulletin of the American Meteorological Society, vol. 96, no. 1, pp. 69-83, 2015.

[27] D. P. Dee, S. M. Uppala, A. Simmons et al., "The ERA-Interim reanalysis: configuration and performance of the data assimilation system," Quarterly Journal of the Royal Meteorological Society, vol. 137, no. 656, pp. 553-597, 2011.

[28] S. Saha, S. Moorthi, H.-L. Pan et al., "The NCEP climate forecast system reanalysis," Bulletin of the American Meteorological Society, vol. 91, no. 8, pp. 1015-1058, 2010.

[29] A. Yatagai, K. Kamiguchi, O. Arakawa et al., "APHRODITE: constructing a long-term daily gridded precipitation dataset for Asia based on a dense network of rain gauges," Bulletin of the American Meteorological Society, vol. 93, no. 9, pp. 1401-1415, 2012.

[30] M. L. Tan, P. W. Gassman, and A. P. Cracknell, "Assessment of three long-term gridded climate products for hydro-climatic simulations in tropical river basins," Water, vol. 9, no. 3, p. 229, 2017.

[31] K. E. Trenberth, "Changes in precipitation with climate change," Climate Research, vol. 47, no. 1-2, pp. 123-138, 2011.

[32] C. Data, Guidelines on Analysis of Extremes in a Changing Climate in Support of Informed Decisions for Adaptation, World Meteorological Organization, Geneva, Switzerland, 2009.

[33] J. Caesar, L. Alexander, B. Trewin et al., "Changes in temperature and precipitation extremes over the Indo-Pacific region from 1971 to 2005," International Journal of Climatology, vol. 31, no. 6, pp. 791-801, 2011.

[34] L. V. Alexander and J. M. Arblaster, "Historical and projected trends in temperature and precipitation extremes in Australia in observations and CMIP5," Weather Climate Extremes, vol. 15, pp. 34-56, 2017.

[35] H. B. Mann, "Nonparametric tests against trend," Econometrica: Journal of the Econometric Society, vol. 13, no. 3, pp. 245-259, 1945.

[36] P. K. Sen, "Estimates of the regression coefficient based on Kendall's tau," Journal of the American Statistical Association, vol. 63, no. 324, pp. 1379-1389, 1968.

[37] R. M. Da Silva, C. A. Santos, M. Moreira et al., "Rainfall and river flow trends using Mann-Kendall and Sen's slope estimator statistical tests in the Cobres River basin," Natural Hazards, vol. 77, no. 2, pp. 1205-1221, 2015.

[38] X. Zhang, L. Alexander, G. C. Hegerl et al., "Indices for monitoring changes in extremes based on daily temperature and precipitation data," Wiley Interdisciplinary Reviews: Climate Change, vol. 2, no. 6, pp. 851-870, 2011.

[39] K. H. Hamed, "Trend detection in hydrologic data: the Mann-Kendall trend test under the scaling hypothesis," Journal of Hydrology, vol. 349, no. 3-4, pp. 350-363, 2008.

[40] N. Endo, J. Matsumoto, and T. Lwin, "Trends in precipitation extremes over Southeast Asia,” Sola, vol. 5, pp. 168-171, 2009.
[41] P. A. O'Gorman, "Sensitivity of tropical precipitation extremes to climate change," Nature Geoscience, vol. 5, no. 10, pp. 697-700, 2012.

[42] L. Zongxing, Y. He, P. Wang et al., "Changes of daily climate extremes in southwestern China during 1961-2008," Global Planetary Change, vol. 80-81, pp. 255-272, 2012.

[43] L. P. Hoang, H. Lauri, M. Kummu et al., "Mekong River flow and hydrological extremes under climate change," Hydrology Earth System Sciences, vol. 20, no. 7, pp. 3027-3041, 2016.

[44] H. T. L. Huong and A. Pathirana, "Urbanization and climate change impacts on future urban flooding in Can Tho city, Vietnam," Hydrology Earth System Sciences, vol. 17, no. 1, p. 379, 2013.

[45] J. J. M. Delgado, H. Apel, and B. Merz, "Flood trends and variability in the Mekong river," Hydrology Earth System Sciences, vol. 14, no. 3, pp. 407-418, 2010.

[46] B. Li, H. Su, F. Chen et al., "The changing pattern of droughts in the Lancang River Basin during 1960-2005," Theoretical Applied Climatology, vol. 111, no. 3-4, pp. 401-415, 2013.

[47] K. Ono, S. Kazama, L. N. Gunawardhana, and K. Kuraji, “An investigation of extreme daily rainfall in the Mekong River Basin using a gridded precipitation dataset," Hydrological Research Letters, vol. 7, no. 3, pp. 66-72, 2013. 